\title{
Flowering phenology change and climate warming in southwestern Ohio
}

\author{
Ryan W. McEwan - Robert J. Brecha • \\ Donald R. Geiger • Grace P. John
}

Received: 6 January 2010/ Accepted: 4 June 2010/Published online: 15 June 2010

(C) Springer Science+Business Media B.V. 2010

\begin{abstract}
Global surface temperature has increased markedly over the last 100 years. This increase has a variety of implications for human societies, and for ecological systems. One of the most obvious ways ecosystems are affected by global climate change is through alteration of organisms' developmental timing (phenology). We used annual botanical surveys that documented the first flowering for an array of species from 1976 to 2003 to examine the potential implications of climate change for plant development. The overall trend for these species was a progressively earlier flowering time. The two earliest flowering taxa (Galanthus and Crocus) also exhibited the strongest shift in first flowering. We detected a significant trend in climate suggesting higher temperatures in winter and spring over the sampling interval and found a significant relationship between warming temperatures and first flowering time for
\end{abstract}

R. W. McEwan $(\varangle)$ · D. R. Geiger · G. P. John

Department of Biology, University of Dayton, 300 College Park, Dayton, OH 45469, USA

e-mail: ryan.mcewan@udayton.edu

D. R. Geiger

e-mail: donald.geiger@notes.udayton.edu

G. P. John

e-mail: johngrap@notes.udayton.edu

\section{R. J. Brecha}

Department of Physics, University of Dayton, 300 College

Park, Dayton, OH 45469, USA

e-mail: robert.brecha@notes.udayton.edu some species. Although $60 \%$ of the species in our study flowered earlier over the sampling interval, the remaining species exhibited no statistically detectable change. This variation in response is ostensibly associated with among-species variation in the role of climate cues in plant development. Future work is needed to isolate specific climate cues, and to link plant phenology to the physiological processes that trigger plant development.

Keywords Climate change - Global warming . First flowering $\cdot$ Minimum temperature

\section{Introduction}

Reports issued over the past 20 years by the Intergovernmental Panel on Climate Change (IPCC) have been increasingly clear about changes currently occurring in Earth systems (Houghton et al. 2001). Most recently, the Fourth Assessment Report (AR4) concluded that "warming of the climate system is unequivocal" (Solomon et al. 2007, p. 7) and that "observational evidence from all continents and most oceans shows that many natural systems are being affected by regional climate changes, particularly temperature increases" (Parry et al. 2007, p. 8). Climate warming has been shown to initiate a complex of ecological responses. In some instances, ecosystem structure may be altered substantially, and 
ecosystem-climate system feedbacks have been identified (Chapin et al. 2008). The spatial distribution of some plants is expected to shift in a warmer climate (Iverson and Prasad 1998; Walther et al. 2002; Woodall et al. 2009), and alterations in migration timing have been documented for a number of animal species (Bradley et al. 1999; Parmesan 2006). These shifts have important ecological implications as some interdependent community relationships could be disrupted (Walther et al. 2002; Parmesan 2006).

Alteration of plant phenology is one of the most readily observable ecosystem reactions to climate change. Numerous studies have indicated shifts in plant phenology related to climate warming (e.g., Orlandi et al. 2005; Nordli et al. 2008). For instance, Fitter and Fitter (2002) found an average advance of 4.5 days in flowering date among the 385 species sampled in a study from south-central England over the four decades prior to the 1990s. Bradley et al. (1999) documented overall changes of 1.2 days per decade in the phenology of various species in recent years compared to the dates measured six decades earlier. Increasingly early plant development has been documented in a number of species and study systems (Abu-Asab et al. 2001; Menzel et al. 2006; Parmesan 2006; Nordli et al. 2008).

Multi-species assessments have yielded some particular hypotheses about the nature of plant phenology change in a warming climate. First, species that flower early in the growing season tend to exhibit a greater shift in flowering time. In some species, this shift may be related to maintaining the adaptive advantage of development in advance of potential competitors in early spring (e.g., Muller 1978). Second, species' reactions to climate change are non-uniform. Bradley et al. (1999) found that while many species had substantially earlier flowering times, other species were "non-responders" that did not change in response to climate warming. The latter likely include species with flowering triggered by photoperiod. This non-uniform response across species has important ecological implications as it creates the potential for climate-response mismatches between ecologically interdependent species (Bradley et al. 1999; Walther et al. 2002; Parmesan 2006).

We examined a 28 -year data set of first flowering observations in southwestern Ohio, USA. Our objective was to investigate potential influences of global change processes on plant phenology and to identify variation in response among species. We hypothesized that $\left(H_{1}\right)$ plants in our study would flower increasingly early in association with a warming climate. We further hypothesized that $\left(\mathrm{H}_{2}\right)$ plants that flower in the early spring would change more substantially than species flowering later in the year.

\section{Methods}

Our analysis was based on flowering phenology observations on a species rich 0.5 hectare tract in Beavercreek, $\mathrm{OH}\left(39^{\circ} 73^{\prime} \mathrm{N}, 84^{\circ} 04^{\prime} \mathrm{W}\right)$ from January 1976 through 2003 (Carol Graff, personal communication). The observations were made every day through spring and summer of each year. A transit was made each morning along a path that circles through the property. Additional observations were made in secondary transits during most days (Carol Graff, personal communication). Across the sampling period, 270 different taxa of both native and cultivated species were observed, though most were observed only a few times, and many were taxonomic varieties. Because we were specifically interested in long-term changes in flowering phenology, in our analyses we only included taxa that occurred in $\geq 16$ of the observation years.

For the purposes of analysis, first flowering dates were converted to ordinal date (mathematical sum of days beginning at 1 January). Simple linear regression analysis was used to test the hypothesis of no change in first flowering date (for each taxon individually) over the sampling interval. In this analysis, year was the independent variable, ordinal date of flowering was the dependant variable, and the regression was considered significantly different from zero at $P \leq 0.05$.

Daily climate data were obtained from the National Climate Data Center for the weather station at the Dayton International Airport (Co-op ID \#332075; located at $39^{\circ} 54^{\prime} \mathrm{N}, 84^{\circ} 13^{\prime} \mathrm{W}$ ). The weather station is located approximately $35 \mathrm{~km}$ from the site of observations. We analyzed mean daily maximum and minimum temperature for each month. A linear regression analysis was performed on the raw monthly data to test the statistical significance of any deviation over time of the temperature trend from zero. Regressions were considered significantly different from zero at $P \leq 0.05$, and highly significant at $P \leq 0.01$. Since we were interested in potential influences of 
temperature changes during the period for which we had observations, we used temperature data for the period 1976-2003.

\section{Results}

We found 15 taxa with at least 16 observations over the 28-year sampling period (Table 1). These included ornamental species, natives to the region, exotic ornamentals, and a variety of life forms including both woody and herbaceous species. First flowering dates ranged from early March through early August (Table 1).

In support of our first hypothesis $\left(H_{1}\right), 9$ of the 15 taxa we tested $(60 \%)$ had a statistically significant negative slope (Table 1; Fig. 1) indicating earlier flowering. For instance, Crocus, Galanthus and Phlox were the three taxa with the most strongly negative slope (Fig. 2) and the regression for each of these was highly significant $(P<0.001$, for all three). In contrast, species such as Ranunculus, Centaurea and Ageratum did not exhibit detectable changes over the sampling period (Fig. 2).

We found some support for our hypothesis $\left(\mathrm{H}_{2}\right)$ that species flowering earlier in the year would have the strongest change in flowering date. Galanthus and
Crocus had the two most negative slopes, indicating the most substantial shift in flowering time, and were also the two earliest flowering species (Fig. 1). Considering only species that flowered before June (ordinal date $\sim 150$ ), there was a highly significant positive relationship $\left(P=0.003 ; r^{2}=0.6\right)$ between flowering date and flowering date change, where species that flowered later in the year also had a less negative slope (Fig. 1; relationship not shown). An analysis that included the whole data set, though, suggested no relationship $\left(P=0.3 ; r^{2}=0.08\right)$, and this was largely caused by two taxa (Phlox and Hosta) that had significantly negative slopes, but were late flowering species (Fig. 1).

Over the sampling period there was a distinct trend in temperature, with increasingly warm temperatures especially apparent for months early in the year (Table 2). Although there was substantial annual variability, mean minimum temperature exhibited a significant (increasing) trend for January, February and June $(P<0.05$; Fig. 3$)$. We also detected a significant trend in mean minimum temperature averaging December through February (Table 2). Mean maximum temperatures in January also increased significantly (Table 2).

Early season temperature changes were strongly correlated to changes in first flowering date of early

Table 1 First flowering date change of plant species monitored for 28 years in southwestern Ohio, USA

\begin{tabular}{|c|c|c|c|c|c|}
\hline \multicolumn{2}{|c|}{ First flowering } & \multirow[t]{2}{*}{ Taxon } & \multicolumn{3}{|c|}{ First flowering change } \\
\hline Date (mean) & $\begin{array}{l}\text { Ordinal day } \\
(\text { mean } \pm \mathrm{SE})\end{array}$ & & Days/year (slope) & $r^{2}$ & $P$ \\
\hline 02 March & $61 \pm 2.8$ & Galanthus sp. (snowdrop) & -1.10 & 0.36 & 0.001 \\
\hline 06 March & $65 \pm 3.2$ & Crocus flavus (crocus) & -1.22 & 0.33 & 0.001 \\
\hline 27 March & $86 \pm 2.0$ & Forsythia sp. (forsythia) & -0.18 & 0.02 & 0.468 \\
\hline 18 April & $108 \pm 1.5$ & Viola pubescens (yellow violet) & -0.58 & 0.35 & 0.001 \\
\hline 19 April & $109 \pm 1.5$ & Malus sp. (crab apple) & -0.45 & 0.25 & 0.014 \\
\hline 23 April & $113 \pm 1.6$ & Ajuga reptans (ajuga) & -0.19 & 0.04 & 0.336 \\
\hline 25 April & $115 \pm 1.3$ & Delphinium consolidate (larkspur) & -0.37 & 0.20 & 0.019 \\
\hline 27 April & $117 \pm 2.2$ & Dicentra spectabilis (bleeding heart) & -0.37 & 0.18 & 0.047 \\
\hline 27 April & $117 \pm 1.2$ & Geranium maculatum (wild geranium) & -0.19 & 0.06 & 0.243 \\
\hline 05 May & $125 \pm 1.9$ & Ranunculus sp. (buttercup) & 0.16 & 0.02 & 0.488 \\
\hline 13 May & $133 \pm 2.3$ & Centaurea cyanus (bachelor's button) & 0.23 & 0.04 & 0.440 \\
\hline 19 May & $138 \pm 1.6$ & Hemerocallis lilioasphodelus (daylily) & -0.40 & 0.16 & 0.044 \\
\hline 14 July & $195 \pm 2.2$ & Phlox sp. (phlox) & -0.91 & 0.50 & $<0.001$ \\
\hline 08 August & $220 \pm 1.9$ & Ageratum sp. (ageratum) & 0.18 & 0.02 & 0.475 \\
\hline 11 August & $223 \pm 2.3$ & Hosta plantaginea (giant white hosta) & -0.64 & 0.20 & 0.039 \\
\hline
\end{tabular}


Fig. 1 First flowering date change (ordinal date) over a 28-year (1976-2003) observation period in southwestern Ohio, USA. Flowering date change represents the slope of the linear regression between first flowering date and year. Darkened symbols represent slopes that were statistically different from zero $(P<0.05)$, and the horizontal dashed line represents no change

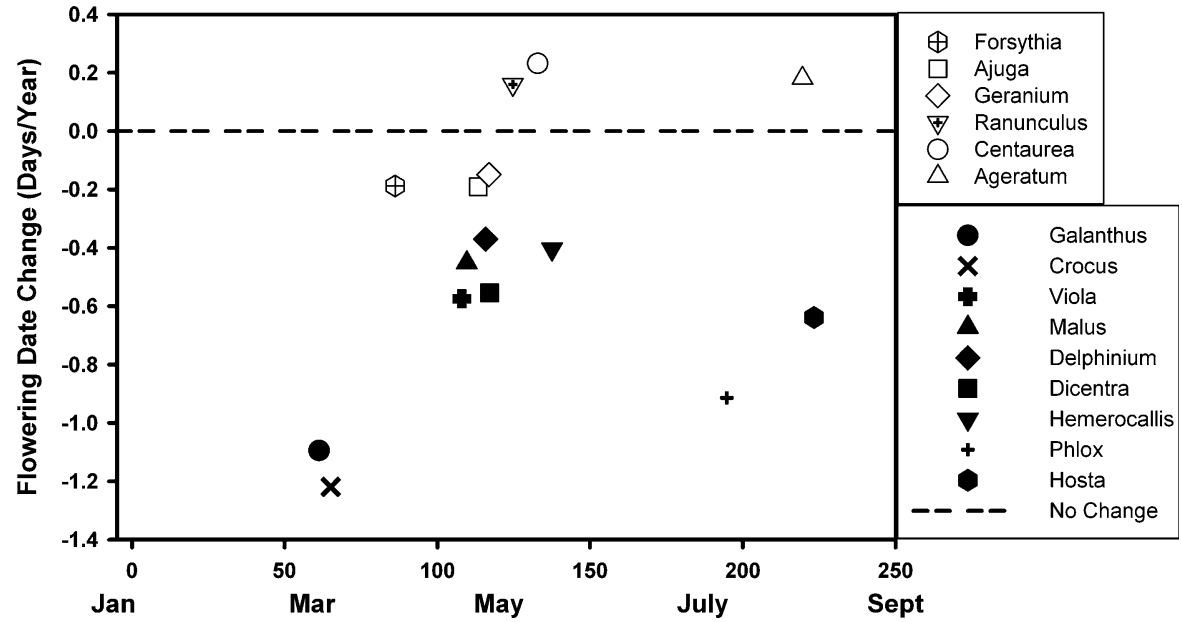

Mean First Flowering Date (Ordinal Date) flowering species (Fig. 4). Mean minimum temperatures for December-February were significantly, and negatively, related to first flowering date in Galanthus $\left(P<0.001 ; r^{2}=0.61\right)$ and Crocus $(P=0.001$; $r^{2}=0.33$ ) (Fig. 4). These two species were the earliest flowering species and also exhibited the strongest shifts in flowering (Table 1; Fig. 1). First flowering dates for Galanthus $\left(P<0.001 ; r^{2}=0.66\right)$ and Crocus $\left(P<0.001 ; r^{2}=0.39\right)$ were also significantly related to mean maximum temperature over the same 3 months (Fig. 4).

\section{Discussion}

A warming global climate has the potential to substantially influence the structure, composition, and function of ecosystems (Parmesan 2006; Chapin
Fig. 2 Response of first flowering date (ordinal date) of selected taxa over a 28-year (1976-2003) observation period in southwestern Ohio, USA. Column of figures on the left represents the three species with the most negative slopes (all significant at $P \leq 0.001$; solid lines) indicating increasingly early flowering. Figures on the right represent the three most positive slopes (none statistically significant, dotted lines). Panels in each column are ordered from earliest to latest flowering
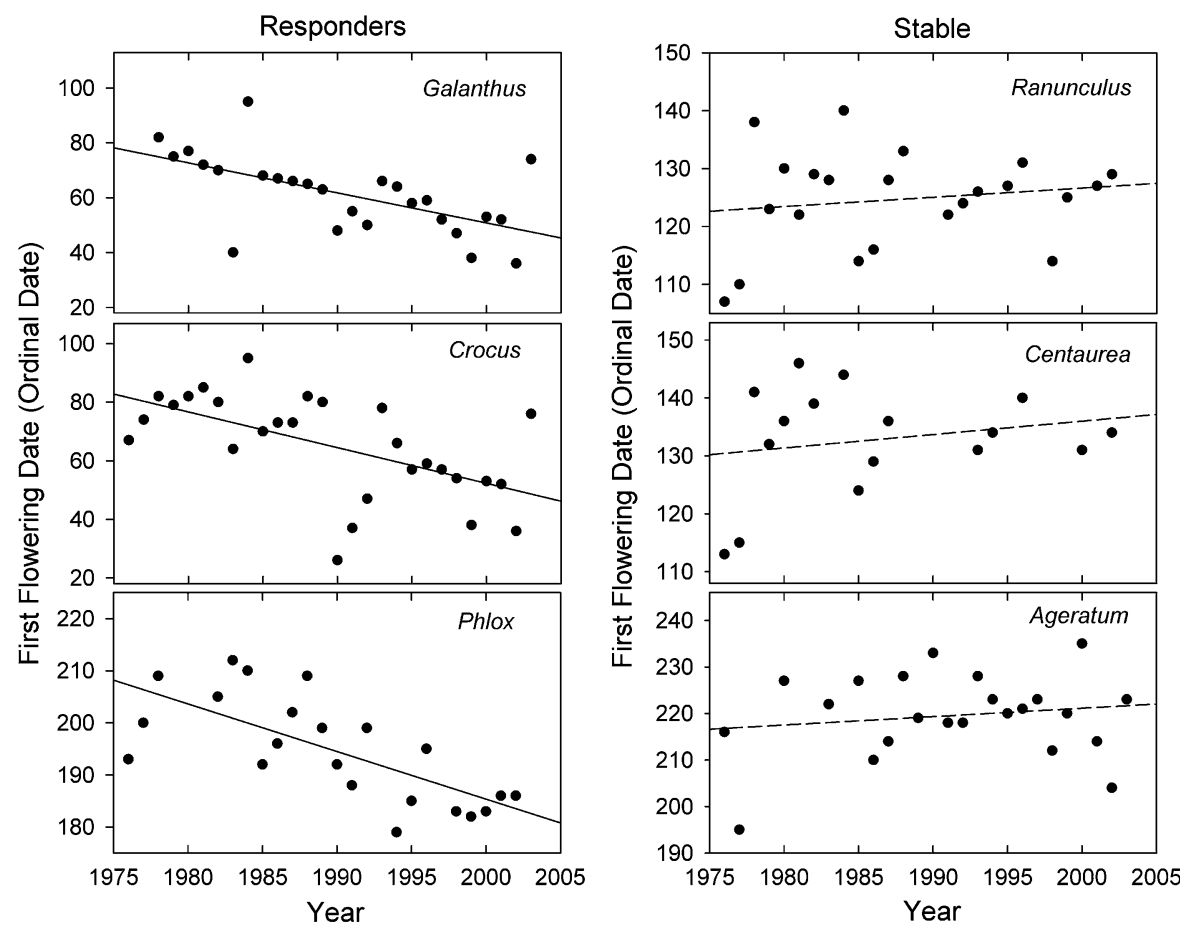
Table 2 Temperature trends from 1976 to 2003 in southwestern Ohio, USA

\begin{tabular}{lcc}
\hline Month & $\begin{array}{l}\text { Minimum } \\
\left({ }^{\circ} \mathrm{C} / \text { year }\right)\end{array}$ & $\begin{array}{c}\text { Maximum } \\
\left({ }^{\circ} \mathrm{C} / \text { year }\right)\end{array}$ \\
\hline December & 0.04 & 0.00 \\
January & $0.19^{*}$ & $0.18^{*}$ \\
February & $0.17^{* *}$ & 0.12 \\
March & -0.01 & $-0.04^{*}$ \\
April & 0.04 & 0.01 \\
May & 0.02 & $-0.05^{*}$ \\
June & $0.06^{*}$ & $-0.03^{*}$ \\
July & 0.01 & $-0.03^{*}$ \\
August & 0.04 & 0.02 \\
December-February & $0.10^{*}$ & $0.13^{* *}$ \\
\hline
\end{tabular}

Slope of the linear regression values for raw data are given $(* P<0.05 ; * * P<0.01)$

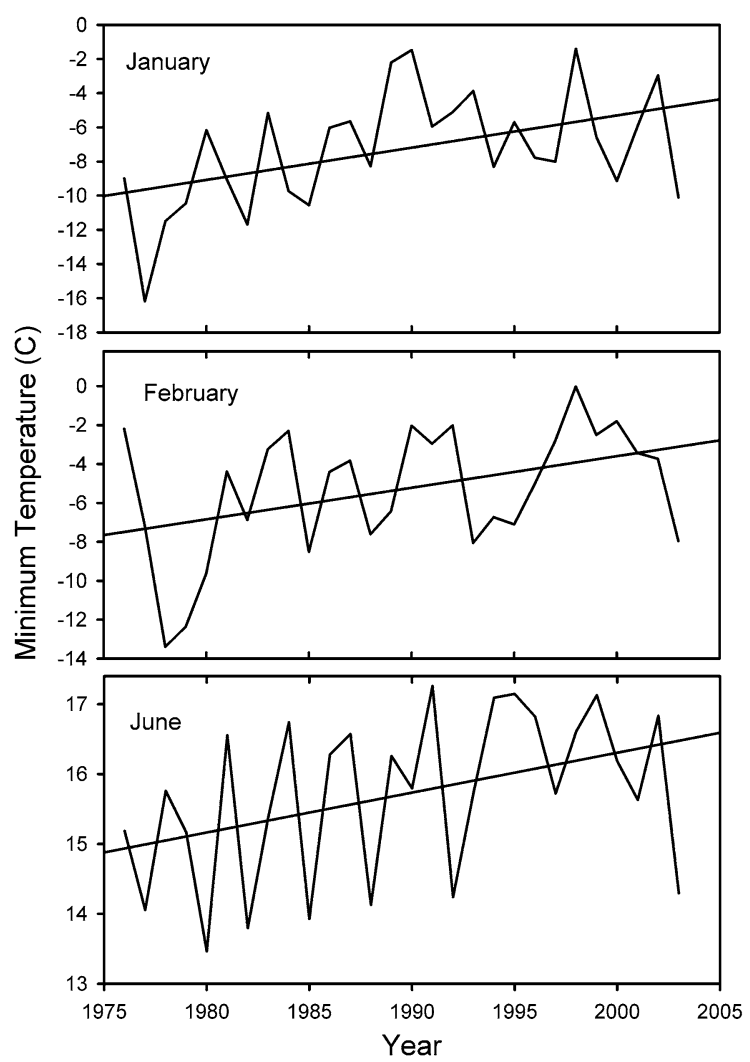

Fig. 3 Temperature trend for selected months over a 28 -year (1976-2003) observation period in southwestern Ohio, USA

et al. 2008). Alteration in the timing of plant phenology is one important potential impact of a warming climate (Bradley et al. 1999; Fitter and
Fitter 2002; Primack et al. 2004; Orlandi et al. 2005). Our data supported the hypothesis $\left(H_{1}\right)$ that first flowering time was increasingly early over the last three decades and was related to an overall trend of increasing seasonal temperature. Of the species in our study, 60\% exhibited significantly earlier flowering over the study period. Abu-Asab et al. (2001), similarly, found an increasingly early flowering time for a variety of species correlated with an increase in minimum temperatures in the Washington, DC area. Similarly, Houle (2007) found an advance of 2-6 days per century in a study of flowering phenology in eastern Canadian forest species. That study found that a shift of 2-3 days was correlated with a change of $1^{\circ} \mathrm{C}$ of temperature rise, and showed a stronger effect on species found in Montreal, a large urban area which experiences a heat-island effect (Houle 2007). Our data add to a growing body of work (e.g., Fitter and Fitter 2002; Parmesan and Yohe 2003; Nordli et al. 2008) that indicates plant phenology is changing markedly in association with a warming climate.

In addition to the overall trend of increasingly early flowering, we hypothesized $\left(\mathrm{H}_{2}\right)$ that early flowering plants would exhibit a more marked change in phenology than later flowering species. Hypothetically, early-spring flowering species, which exploit a narrow window in time before leaf-out of other species, would have evolutionary pressure to track climatic conditions and begin development at the earliest opportunity. A number of studies have supported this concept (e.g., Abu-Asab et al. 2001; Fitter and Fitter 2002; Walther et al. 2002). For instance, Parmesan and Yohe (2003) found that $62 \%$ of early spring phenophases shifted earlier in response to climate warming. We found some support for this postulate as the earliest flowering species also exhibited the strongest change in first flowering; however, two of the latest flowering species also exhibited substantially earlier flowering. Physiological work is needed to understand the mechanism(s) underlying tracking of winter temperature in early flowering species, and more survey work is needed to identify taxonomic patterns in flowering response.

Beyond variation in flowering phenology across the growing season, we found that some species responded to climate warming, while others were stable. Bradley et al. (1999), focusing only on springtime events, found that approximately one-third of the phenophases 
Fig. 4 Relationship between first flowering date change (ordinal date) and mean temperature December through February over a 28-year (1976-2003) observation period in southwestern Ohio, USA. All relationships were significant at $P \leq 0.001$

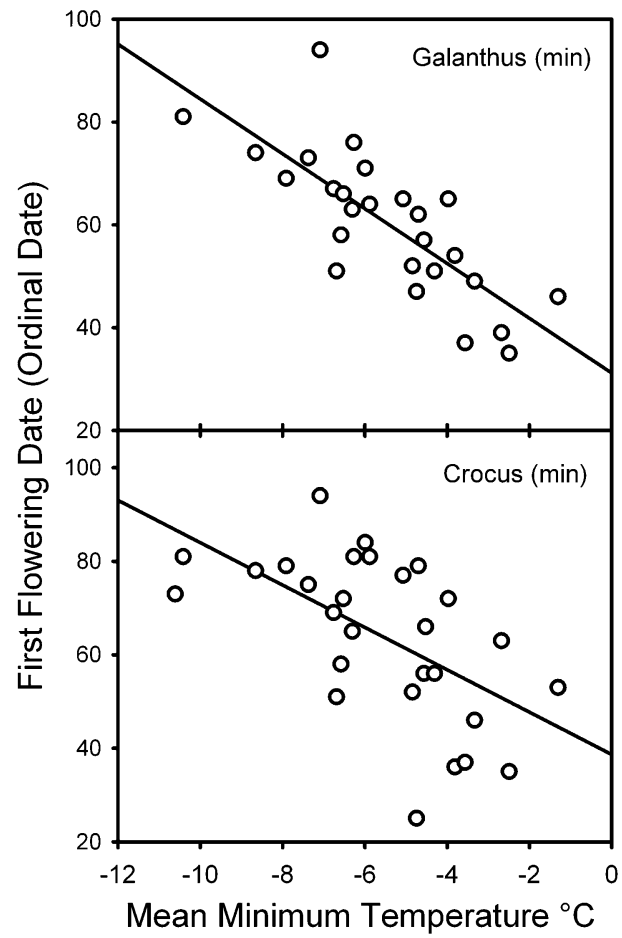

they observed (including animals as well as plants) were earlier as a result of climate change, one-third were later, and one-third remained stable. In our study, plants that flowered in the range of 100-150 ordinal days (late April through early June) exhibited a variety of responses including significantly earlier flowering and non-response (Fig. 1). The cause of this variation is unknown. These species encountered identical climatic stimuli, so the cause of these differences must be linked to variation in the role of climate as a developmental trigger. We hypothesize that winter and early spring warming accelerated growth of some taxa such that they arrived at a requisite developmental threshold sooner, while other species were either (1) not accelerated by climate warming or (2) development was accelerated but flowering was unchanged because the flowering trigger was photoperiod (which is stable). Bradley et al. (1999) argue that flowering in many species is cued by photoperiod and therefore will not respond to climate warming. This suggests the possibility of a lag effect in some species that may reach a growth threshold earlier but flowering is stalled because photoperiod is unchanged. Future work is needed that focuses on the particular relationship(s) between temperature (and other climate cues), photoperiod, developmental pathways, and physiological activity in plant species.

Climate change has wide ranging implications for ecosystems, and one of the most important is the potential for alterations in the life-history timing of individual species. Our data suggest that (1) some plant species are responding to variation in climate, (2) across the growing season the reaction is nonuniform and (3) even within season, some species react to changes in climate while others are nonresponders. Given the potential importance of climate-response mismatches between community members, understanding the basis of plant phenology response is an important next step for research (Parmesan 2006). In particular, we suggest that future work is needed that bridges the gap between pattern (plant phenology response) and process (plant developmental physiology) in relation to particular climatic cues.

Acknowledgments This analysis was made possible by three decades of careful observations by Carol Graff. We are appreciative of her careful botanical efforts and grateful that she was willing to share her data. Comments by Amy L. GoffYates and two anonymous reviewers greatly improved this manuscript. 


\section{References}

Abu-Asab MS, Peterson PM, Shetler SG, Orli SS (2001) Earlier plant flowering in spring as a response to global warming in the Washington, DC, area. Biodivers Conserv 10:597-612

Houghton JT et al (eds) (2001) Climate Change 2001: the scientific basis. Contribution of working group I to the third assessment report of the Intergovernmental Panel on Climate Change. Cambridge University Press, Cambridge

Bradley NL, Leopold AC, Ross J, Huffaker W (1999) Phenological changes reflect climate change in Wisconsin. Proc Natl Acad Sci USA 96:9701-9704

Chapin FS, Randerson JT, McGuire AD, Foley JA, Field CB (2008) Changing feedbacks in the climate-biosphere system. Front Ecol Environ 6:313-320

Fitter AH, Fitter RSR (2002) Rapid changes in flowering time in British plants. Science 296:1689-1691

Houle G (2007) Spring-flowering herbaceous plant species of the deciduous forests of eastern Canada and 20th century climate warming. Can J For Res 37:505-512

Iverson LR, Prasad A (1998) Predicting abundance of 80 tree species following climate change in the eastern United States. Ecol Monogr 68:465-485

Menzel A et al (2006) European phenological response to climate change matches the warming pattern. Global Change Biol 12:1969-1976

Muller RN (1978) The phenology, growth and ecosystem dynamics of Erythronium americanum in the northern hardwood forest. Ecol Monogr 48:1-20

Nordli Ø, Wielgolaski FE, Bakken AK, Hjeltnes SH, Måge F, Sivle A, Skre O (2008) Regional trends for bud burst and flowering of woody plants in Norway as related to climate change. Int J Biometeorol 52:625-639
Orlandi F, Ruga L, Romano B, Fornaciari M (2005) Olive flowering as an indicator of local climatic changes. Theor Appl Climatol 81:169-176

Parmesan C (2006) Ecological and evolutionary responses to recent climate change. Annu Rev Ecol Evol Syst 37: 637-669

Parmesan C, Yohe G (2003) A globally coherent fingerprint of climate change impacts across natural systems. Nature 421:37-42

Parry ML, Canziani OF, Palutikof JP, van der Linden PJ, Hanson CE (eds) (2007) Climate change 2007: impacts, adaptation and vulnerability. Contribution of working group II to the fourth assessment report of the Intergovernmental Panel on Climate Change. Cambridge University Press, Cambridge

Primack D, Imbres C, Primack RB, Miller-Rushing AJ, Tredici PD (2004) Herbarium specimens demonstrate earlier flowering times in response to warming in Boston. Am J Bot 91:1260-1264

Solomon S, Qin D, Manning M, Chen Z, Marquis M, Averyt KB, Tignor M, Miller HL (eds) (2007) Climate change 2007: the physical science basis. Contribution of working group I to the fourth assessment report of the Intergovernmental Panel on climate change. Cambridge University Press, Cambridge

Walther GR, Post E, Convey P, Menzel A, Parmesan C, Beebee TJC, Fromentin JM, Hoegh-Gulberg O, Bairlein F (2002) Ecological responses to recent climate change. Nature 416:389-395

Woodall CW, Oswalt CM, Westfall JA, Perry CH, Nelson MD, Finley AO (2009) An indicator of tree migration in forests of the eastern United States. For Ecol Manag 257:14341444 